\title{
In-Class Simulation Games: Assessing Student Learning
}

\author{
Kenneth J. Klassen \\ Brock University, St. Catharines, \\ ON, Canada
}

kklassen@brocku.ca

\author{
Keith A. Willoughby \\ Bucknell University, Lewisburg, \\ $P A$, USA
}

kwilloug@bucknell.edu

\section{Executive Summary}

As instructors continue developing useful learning tools for their classrooms, games have become one popular alternative. This paper explains an inventory simulation game, two methods for evaluating whether students learn from playing the game, and the results from two experiments evaluating student learning.

An effective game will help students understand concepts more quickly and remember them better than from a lecture. The game used here is a simulation of an inventory system, where student teams place orders for an item on a monthly basis (based on limited knowledge of prior demand), and then the instructor informs them what the demand is for that month. There are holding costs for items not sold and shortage costs if they run out of items. The students then place their order for the next month.

To evaluate student learning, two methods were used: a before-and-after questionnaire, and playing the game twice. Both methods allowed for an initial benchmark to be established, followed by a measure of how much students improved. For the questionnaire, answers were scored and a paired-comparison t-test was calculated to assess learning. When the game was played twice, a few things were calculated regarding student performance, including the change in student profits.

Most results point to the conclusion that students learned from the game. Basic inventory knowledge increased, students gained an appreciation for the complexity of inventory issues and of decision making in general, and students enjoyed the game and thought it was a worthwhile learning experience. It was evident that many students grasped the larger strategic issues and were beginning to apply them more broadly. Although not all changes were statistically significant, most did improve, suggesting that students developed a deeper hands-on understanding of the issues.

The current study is confirmatory in the general use of simulation games, although it adds to existing literature in that little exists on operations management and information systems games and their assessment. Also, this study involves two independent assessments of the same game, two different instruments, and two different universities.

Keywords: Assessment, Learning, Classroom, Games, Simulation

Material published as part of this journal, either on-line or in print, is copyrighted by the publisher of the Journal of Information Technology Education. Permission to make digital or paper copy of part or all of these works for personal or classroom use is granted without fee provided that the copies are not made or distributed for profit or commercial advantage AND that copies 1) bear this notice in full and 2) give the full citation on the first page. It is permissible to abstract these works so long as credit is given. To copy in all other cases or to republish or to post on a server or to redistribute to lists requires specific permission and payment of a fee. Contact Editor@JITE.org to request redistribution permission.

\section{Introduction}

Games become more useful pedagogical tools as the IT infrastructure for developing them and implementing them in the classroom improves. Many instructors are using one or more games to enhance delivery of their courses, and successful games have been disseminated to others through various mediums. For example, Heineke \& Meile (1995) developed an entire book devoted to games 
and exercises for teaching concepts in operations management. Although it is clear that students generally enjoy in-class games, it is at times unclear if learning occurs during these exercises. It is difficult to separate learning that occurs during games from other forms of learning (e.g., lecture, reading the text, working on practice problems). Even if this is possible, there may not be class time available to carry out the assessment.

This research addresses both of these challenges in two experiments at two universities, considering learning outcomes from an inventory simulation game that was developed in 1996 at the University of Calgary. As the game has been disseminated over the years, it has been used at quite a number of schools in the introductory operations management class. Running the game in class requires use of a computer to track students' progress. Students are forced to understand and make rational decisions regarding a number of opposing aspects through time. Games of this type (simulation) can be used in various disciplines (including information systems) and thus the results from this study should be generalizable to other situations. The success of the game is based on positive student response to the exercise in terms of the deeper understanding they have of the complexity of decision-making and due to their enjoyment of it. It also provides a context in which to teach specific topics after the game has been played.

The overall goal was to determine if the students achieved a better understanding of inventory management in general, and/or a better understanding of specific topics (e.g., how to make calculations). In the absence of other teaching on the topic, it is expected that learning will indeed occur. When used in conjunction with other teaching, it is hoped that a deeper understanding of overall issues will be evident. A limitation of this study is the small sample size. However, it is challenging to find class time to increase this.

This paper will conduct a brief review of the literature, explain the inventory game used, review the methodology used (including development of the instruments) for evaluation and assessment, and report on results from the assessment.

\section{Literature Review}

In a broad sense, the use of games as part of the educational environment fits into the philosophy of active learning and constructivism. Kohn (1997) suggested that in order to promote a deeper understanding of material, students ought to be engaged with what they are doing. Passman (2001) reported on the benefits of adopting a more constructivist, student-centered model of teaching (for a detailed discussion of constructivism, see Applefield, Huber, Moallem (2000)). McKeachie (1994) stated that involving students as active participants results in a positive learning experience. More specifically, McKeachie explained that learning is enhanced if students make decisions and then need to respond to the consequences of each decision.

There is widespread use of games and simulations within business school curricula. Faria (1998) reported that in a recent survey of accredited business schools, fully $97.5 \%$ of them used simulation games in part of their courses. A majority of these games addressed marketing or strategic policy issues. Bodo (2002) discussed the development of an in-class simulation of the classic prisoner's dilemma game with student-designed strategies. Innovative technologies are also adopted in the operation of games. For instance, Doyle and Brown (2000) implemented a business strategy game using e-mail and videoconferencing that involved five teams of postgraduate business students from universities in Ireland, France, and the US. In addition, managers have received some exposure to simulation environments. Levine (1998) discussed a leadership game, while McCune (1998) reported on a business management simulation for executives.

It is also apparent in the literature that students support the use of games for educational purposes. Teach (1993) surveyed a number of graduates from a variety of U.S. business schools. Simulations and games 
rated quite highly. Students reported that these exercises developed their abilities to solve problems systematically, perform forecasts in uncertain environments, and to measure objectives. (Interestingly, respondents rated the traditional "lecture" method quite poorly, overall).

Not surprisingly, instructional support for games has improved lately. For instance, in their book of classroom games, Heineke \& Meile (1995) provide a copy of student handouts, instructional tips, suggested time frames for game completion and questions for discussion to accompany each game they describe. Also, guidelines for developing useful games have been developed by Heineke \& Meile (2000), who suggested that for games to be effective, they should:

- provide an "aha" effect - the insight gained should be unknown until the game is played,

- require students to generate data (rather than be given data) in order to generate deeper understanding,

- be low stress for the students, and

- use simple materials.

Also, Heineke \& Meile (2000) state that the instructor must be well prepared. It is best to run through the game entirely before using the game in class.

Researchers have analyzed other features of business simulations. Reall, Bailey and Stoll (1998) suggested that during the operation of a game, an individual may behave in a manner inconsistent with nongame-situation moral reasoning. In short, an individual may act less ethically in a game situation than they would in real life. The study did not test this, but may suggest further that an individual will take more risks in a game than otherwise. Note, though, that this is the purpose of many games - to try new things and to learn in a safe environment.

Neal (1997) indicated that even though most business simulations are conducted in a competitive manner (with the team earning the most profit deemed the winner), this may not be the best performance measure. The earning of significant profit levels may not result in commensurate student learning. However, it should be noted that this drawback is non-consequential if grades are not attached to game performance.

Schwartzman (1997) observed that games cultivate a learning environment. Although the measurement of student learning is by no means a trivial task, there have been some attempts to assess the level of learning experienced by those participating in a game. Gremmen and Potters (1997) divided their macroeconomics students into two sets; those who played the game, and those who had been exposed only to lecture material. Both groups were given the same multiple-choice exam, covering various economic concepts. They found that students who had participated in the game fared much better than the other group. Kraiger and Cannon-Bowers (1995) reported on the development of a training simulation for a naval decision-making task. Students exposed to greater training content performed better on exams. In a game devoted to strategic management learning, Wolfe and Chanin (1993) discovered that all groups, regardless of their initial skill levels, improved their knowledge. Another study (Santos, 2002) discussed an interactive teaching tool to introduce students to overall consequences of monetary policy. This Financial System Simulator permitted students, representing nations, to interact with each other rather than with a computer. Post-game surveys showed that students gained enhanced monetary policy understanding. Westbrook and Braithwaite (2001) designed an educational game focused on the health care system. Learning outcomes were improved, as shown by pre- and post-game student questionnaires as well as a focus group participant session.

Thus, prior studies report that learning value was achieved. The current study is confirmatory in the general use of simulation games, although it adds to existing literature in that little exists on operations management and information systems games and their assessment. Specifically, despite the importance of the topic for business students and managers, there is no mention of any inventory management 
games in the literature. Also, this study involves two independent assessments of the same game, two different instruments, and two different universities. Thus, a broader understanding of the learning from the game is gained and insight is provided into the relative effectiveness of the two instruments.

\section{Description of the Inventory Game}

This inventory game is a simulation of a sporting goods retailer who needs to make appropriate ordering decisions for one type of hockey stick. Specifically, students decide when and how many hockey sticks to order every month for an entire year. The game takes between 20 and 40 minutes of class time and was initially developed to:

- enhance learning (with the assumption that learning is done better by doing than by just listening, reading, or writing),

- develop an enjoyable learning experience,

- familiarize students with basic inventory concepts,

- give students a chance to test their intuition, and to

- demonstrate to students how frustrating it can be to make decisions under uncertainty.

To play the game in class, students are divided into groups of 3-6 members each and are given the instructions (partial instructions are outlined in Appendix 1). They are also provided with some example calculations and a worksheet to track their inventory levels through time. To start, students determine their order quantity for the first month. Once all groups have reported their orders and the instructor has entered these on a spreadsheet (which is projected for the class), the instructor informs students what the demand actually is for that month (pre-determined randomly, given the parameters). The spreadsheet automatically calculates profit (or loss) for each group, after which groups plan their order for the next month. Throughout the game students compare their profit to date with other groups and at the end of the game students compare their total profit to the maximum total that could have been achieved if they had known demand a priori (more on this later).

A slightly modified version of the game has been used at times. This version requires students to implement forecasting techniques a little differently and also assumes demand follows a normal distribution (instead of uniform). Students are given demand figures over the past two years (for a similar hockey stick). Using this data, they are instructed on how to determine the mean and standard deviation of demand for any month in the current year, as follows:

$$
\text { Demand }=\operatorname{Normal}((\text { D2 }+(D 1 * 3)) / 4 \text {, absvalue }(D 1-D 2))
$$

where: $\quad$ D1 is demand for this month last year

D2 is demand for this month 2 years ago

Thus, they have the parameters of the normal distribution as well as the trend over the last two years to use for their forecast. Note that students do not need to use the above formula; they may simply use intuition based on prior demand. This helps simplify the game to enhance both learning and enjoyment. With this version of the game, the student experience is similar, although students might feel that there is more uncertainty (based on informal comments). The uncertainty may result because there are no maximum and minimum values given for demand (as is done with the uniform distribution), although the actual month-to-month variation in the two versions of the game is similar.

\section{The Assessment Instruments}

Developing effective assessment instruments proved to be a challenging task for a number of reasons. For one thing, it was desirable to separate learning as a result of the game from the learning gained as a result of other pedagogical techniques used to teach this topic. Since the game is relatively short and is 
followed by lecture and case studies on the same topic, it would not work to simply test them at the end of the material. Secondly, some prior studies have used a game for one group of students and not for others, and then compared performance. However, there was a strong sentiment not to "deprive" any students of playing the game due to the consistently positive response from students over the years. Third, it was desirable to determine students' understanding before playing the game in order to compare it to knowledge after the game. Thus, it was undesirable to simply have a test at the end. In order to get accurate readings on relative before and after performance, it is best if the "before" results for each student can be compared to the "after" results for the same student. However, this may require knowing which student supplied which answers and which students had read the chapter materials (to see how much exposure they had to the content before the game). Students are reluctant to give this information in the fear that it may be used for grading purposes. Fourth, the game already uses a fair amount of class time; extra assessment activities will require even more of this scarce resource. Fifth, despite extensive use of the game and the intuitive understanding that the game was useful, it was initially difficult to put into words (for a questionnaire) exactly what the learning outcomes were. Finally, it was unclear whether a questionnaire could get at the learning that took place or whether it was necessary to check learning with another run of the same game (using different demand figures).

As a result, two different evaluations were used; one at each of two different schools. The first used before and after questionnaires (similar to the method used by Westbrook and Braithwaite, 2001). Thus, the first questionnaire was given, the game was played, and the second questionnaire was given - all before any portion of the chapter was taught. The questions were purposely very simple as it was assumed that students had never had any teaching on inventory management. On a side note, it was an interesting and somewhat unnerving experience for the students to do a "test" without having been taught anything about the material.

Appendices 2 and 3 include the two questionnaires. Considering the individual questions, Question 1 was an attempt to understand if students understood the purpose of inventory management (the big picture) either before or after the game was played. Question 2 tested whether they understood basic inventory concepts, particularly the concepts of stock remaining from a prior period, and running out of stock. This question was identical on the second questionnaire except different numbers were used. The third question tested students regarding relevant costs in an inventory ordering decision. It was later realized that the fifth option in this question (costs of managing the inventory, referring to the management time required) could be ambiguous. However, students did not appear confused by this terminology. The fourth question was included to see if the understanding of complex business decisions made under uncertainty was enhanced through this exercise. The first questionnaire also asked if they had read the chapter or class notes before the game, the assumption being that students that had read the material would have a better understanding. If so, this could be removed as a confounding factor. Because of these last two questions, it was felt that students would not answer honestly if they were required to supply their names. Thus, they were encouraged to give an identifier (such as "banana" or "dude") that they would use for both questionnaires. Thus, individual students could be matched before and after but they remained anonymous. The second questionnaire had two additional questions, asking if the students thought it was a worthwhile experience (testing to see if they enjoyed it) and asking an open-ended question about the most important thing they learned from the game (to check broader understanding).

The second evaluation method was designed to eliminate any questionnaire or testing bias. It involved playing the game twice, to see if student performance improved the second time. Due to semester scheduling issues, the game was played before and after the lecture on inventory management, in two different class periods. In this case the game may have tested both learning from the first playing of the game as well as learning from the lecture. However, the instructor was careful not to discuss any aspects of the game or its strategy between the two games and a different set of demand values were used the second time. In any case, the game involves a much more complex environment than can be handled with the 
inventory techniques taught in this introductory operations management class. Basically, the only way to optimize such inventory replenishment decisions would be to use the Wagner-Whitin dynamic programming method (Silver, Pyke and Peterson, 1998). Thus, whether or not students have had a lecture on the material, they are forced to use intuition and deeper understanding instead of the simple formulas learned.

For the second playing of the game, different demand patterns were used, meaning the best possible ordering strategy and financial performance differed. As a result, profits could not be compared directly. Thus, a closeness measure was developed to measure how close each team was to the optimal profit possible, as shown in equation 2.

$$
\text { Closeness }=\frac{\text { Profit of Student Team }}{\text { Optimal Profit }}
$$

This measure will vary between 0 and 1, the closer it is to 1, the better the performance of the team.

Another measure used relates to the optimal ordering strategy. For the particular demand patterns used, although they differ from one another, the best strategy is usually to order in only about half the months (determined using the Wagner-Whittin algorithm, as mentioned above). Students initially tend to think they should order every month (they don't think about the balance between ordering costs and holding costs, not realizing that ordering costs are relatively high). In the two games, the optimal strategy was to order in six of the months (a different set of six months the second time). Recall that the instructor was careful not to discuss game strategy between the games and did not show the optimal ordering strategy after the first game; only the optimal profit was given. Thus, it can be deduced that the closer a group is to ordering in six of the twelve months, the better their strategy. To measure this, the difference between the optimal number of months and the actual number of months in which orders were placed was calculated (for all groups). The differences in the first running of the game and the differences in the second running were compared statistically.

For both methods, the authors' classes were used for the experiment. These are university students in the business program, primarily $3^{\text {rd }}$ year students, but some were $2^{\text {nd }}$ or $4^{\text {th }}$ year students. The first experiment was carried out in a class where 27 students were in attendance. The method of playing the game twice was carried out in two classes, with a total of 14 teams the first time and 13 the second time. As such, individual teams were not compared; rather overall performance of the class was measured. It is felt that using different teams the second time enhances learning, as students have a different set of peers to gain understanding from.

\section{Results}

\section{Questionnaires}

Overall, the questionnaires revealed that students had a better understanding of inventory management issues after the game than before. For the first three questions the alternative hypothesis tested was whether students improved; whether they answered more accurately after the game. These three questions could potentially be treated as qualitative data, comparing the proportion correct after the game to the proportion correct before. However, once they are scored, it is equally valid to perform a quantitative matched pairs test of means. Also, using the matched pairs option provides a better student-by-student comparison. Table 1 gives results for the first three questions, including $p$-values from the matched pairs test. Microsoft Excel was used for all data manipulation and statistical tests. 


\begin{tabular}{|c|c|c|c|c|c|c|}
\hline Question & $\begin{array}{c}\text { Potential \# } \\
\text { Points (27 } \\
\text { students) }\end{array}$ & $\begin{array}{c}\text { Score } \\
\text { Before }\end{array}$ & $\begin{array}{c}\text { Score } \\
\text { After }\end{array}$ & $\begin{array}{c}\text { p-value } \\
\text { (one-tail) }\end{array}$ & $\begin{array}{c}\text { Proportion } \\
\text { Correct } \\
\text { Before }\end{array}$ & $\begin{array}{c}\text { Proportion } \\
\text { Correct } \\
\text { After }\end{array}$ \\
\hline $\mathbf{1}$ & 54 & 10 & 20 & $\mathbf{0 . 0 2 4}$ & $18.5 \%$ & $37.0 \%$ \\
\hline $\mathbf{2}$ & 27 & 22 & 17 & $\mathbf{0 . 9 5 2}$ & $81.5 \%$ & $63.0 \%$ \\
\hline $\mathbf{3}$ & 135 & 77 & 103 & $\mathbf{0 . 0 0 1}$ & $57.0 \%$ & $76.3 \%$ \\
\hline
\end{tabular}

Table 1: Results of before and after questionnaires: Questions 1-3

First, recall that students were not taught anything about inventory management before these questionnaires; thus, scores would be expected to be low, especially before the game. Also, students all reported not reading the inventory chapter or other material before the class. This was not unexpected, since this class met every day of the week and there was an assignment due the day of the game, reducing their opportunity to read the material. The instructions for the game go over a few inventory concepts, but these are directly related to the game; they are not generalized.

Questions 1 and 3 show strong evidence that there was improvement after the game. However, Question 2 gives no evidence of improvement, as there was actually a drop in performance on this question. It seems students confused themselves with the additional information they gained from playing the game, thinking this question was more complex than it actually was. One possible confusing factor may be that the game includes shortage costs, but this question did not (the idea was to make it simple). A few students were confused on the after questionnaire because they were looking for shortage costs in the question. Possibly the question should have included a statement such as "ignore any costs not mentioned".

Questions 4 and 5 use ranked (or ordinal) data.

Question 4 asked how difficult students feel inventory decisions are. It was designed to see how students perceive the complexity of inventory-related decisions. It is felt this may also be an indication of their before and after understanding of business decisions in general; students may under-estimate the complexity of decisions in the real world. Since we have matched pairs, the sign test is most appropriate for this data, using the alternative hypothesis that students will feel it is more difficult after the game. The sign test is made possible by coding the responses from 1 to 5 , with "very easy" being labeled 1 and "very difficult"

\begin{tabular}{|l|c|c|}
\hline Question 4 & $\begin{array}{c}\text { Number } \\
\text { Before }\end{array}$ & $\begin{array}{c}\text { Number } \\
\text { After }\end{array}$ \\
\hline Very Easy & 0 & 0 \\
\hline Easy & 0 & 0 \\
\hline Moderate & 8 & 5 \\
\hline Difficult & 18 & 14 \\
\hline Very Difficult & 1 & 8 \\
\hline & & \\
\hline p-value & & $\mathbf{0 . 0 1 0}$ \\
\hline
\end{tabular}

Table 2: Results of before and after questionnaires: Question 4 being 5. Results are summarized in Table 2.

The sign test reveals a significant change, with overwhelming evidence that students felt that inventory management was more complex after the game than they did before.

Question 5 (only on the second questionnaire) asked if the game was worthwhile, to get an indication whether students enjoyed and felt they learned from the game. As can be seen in Table 3, the vast majority felt the game was a very worthwhile learning experience.

In their responses to Question 6 (an open-ended question asking about the most important thing learned from the game), a few students mentioned very game-specific learning, which was positive but did not show that they were generalizing the concepts. However, most students understood the wider applicability. A number of students

\begin{tabular}{|l|c|}
\hline \multicolumn{1}{|c|}{ Question 5 } & $\begin{array}{c}\text { Number } \\
\text { After }\end{array}$ \\
\hline Not at all & 0 \\
\hline Somewhat & 1 \\
\hline Moderately & 5 \\
\hline Very Much & 21 \\
\hline
\end{tabular}

Table 3: Results from after questionnaire: Question 5 
pointed to the difficulty of predicting demand and some pointed to the need for analysis when making decisions (instead of just guessing). Others mentioned the importance of focusing on the long-term results, which is likely due to the fact that many groups start out with little profit or even losses at the beginning of the game, but by the end, all made a profit.

\section{Running the Game Twice}

As mentioned above, the groups for the two times the game was played varied in number and in composition because the second game was run on a different day than the first. This is a potential confounding factor, since there were a few students present for the first game who were not present for the second game and vice versa. However, as stated above, the goal in this case was to measure overall class learning instead of comparing specific groups to each other. On a side note, students enjoyed playing the game twice; some even wanted to play a third time to see if they could improve further.

The average closeness measure during the first game was 0.825 , and during the second it was 0.839 . Comparing these using a one-tailed t-test, the p-value is 0.279 , showing no evidence that the groups were more profitable the second game. However, during the second running, one group did exceptionally poorly; the difference between this group and the next worse group was considerably larger than the difference between any other two groups. Possibly this group had a number of members that were not present for the first game. Thus, if this group is considered an outlier and removed, the average closeness measure for the second game is 0.851 , with the $\mathrm{p}$-value comparison changing to 0.118 . Thus, there is still no evidence of an improvement, although it is considerably closer to being significant than before.

The second measure for this measurement technique showed a more remarkable improvement. In the first game, groups placed orders in $82.7 \%$ of the months (on average). The second time they ordered in only $53.2 \%$ of the months. In both cases, the best solution was to order in $50 \%$ of the months. As explained above, individual group differences from the optimal number of months were calculated. Thus, ordering in too few months was as equally negative as ordering in too many months, with the differences getting larger as the number of months got farther from optimal. These were compared using a standard t-test for comparing means. The alternative hypothesis was that the differences were lower the $2^{\text {nd }}$ time around. The result showed overwhelming evidence that groups were closer to ordering in the optimal number of months the second time the game was played ( $\mathrm{p}$-value $=0.0045$ ).

\section{Discussion and Concluding Remarks}

All results (except one) point to the conclusion that students learned from the game. Basic inventory knowledge was tested in the first 3 questions on the questionnaire. Two of these showed significant improvement; one showed no improvement. However, these 3 questions may be less important than the rest of the results, as the rest tested on a more general, conceptual level. Question 4 showed that students gained an appreciation for the complexity of the issues and of decision making in general. Question 5 and the comments from the groups that played twice showed that students enjoyed the game and thought it was a worthwhile learning experience. Both question $6\left(1^{\text {st }}\right.$ study) and the reduction in the number of months in which orders were placed $\left(2^{\text {nd }}\right.$ study) demonstrated that many students grasped the larger strategic issues and were beginning to apply them more broadly. The increase in the closeness measure, while not statistically significant, did show that students were closer to the optimal solution the second time they played. In this experiment both measures showed improvement, with one being highly significant. This demonstrates a deeper hands-on understanding of the issues necessary to do well in the game.

Thus, this study has confirmed prior research that games are effective in enhancing learning. In this particular case, two different experiments at different schools support this, lending credibility to this conclusion. This study raises the interesting question of how to assess learning from a particular pedagogi- 
cal technique (without including learning from others). For instance, some prior studies report that students who had played a game performed better on a test, but how do we know for sure if these students didn't also study harder? The best way to test learning from a game is likely either with before and after questionnaires, or by playing the game twice in the same class, thus ensuring that no learning from other sources occurs in between. However, both of these methods require a large amount of time in one class session.

Research illustrates that students are more likely to remember the educational material learned from games than from a typical lecture. This may be the strongest reason to use games in the classroom. Besides this, students likely develop positive feelings toward a course in which games are used, thus improving the chance of paying attention and learning even during other class sessions. A possible drawback to in-class games is the time taken. In general, less material can be covered if a game is used. However, the conceptual learning and the "aha" effect may be much more valuable than the learning of numerous facts. In fact, a well-designed game should actually reduce the class time needed to teach a particular concept (Heineke \& Meile, 2000).

Now considering the inventory game itself, this game meets all the goals mentioned earlier with the possible exception of one. Students gain specific and general conceptual knowledge about inventory, often realizing these through doing instead of by being told. They generate their own data by choosing the size and timing of orders, and the game has simple materials for students' use. The goal that may not be met is that it may not be low stress. Students work hard to make the correct decisions, some even using calculators to try and make better decisions. However, this turns out to be a good team exercise, where members need to rely on others to gain understanding. It is complex enough that few can grasp all decision factors on their own.

As this game has been revised over the years, there has been a gradual push to add complexity (in the attempt to add more realism). However, it is proposed that this is a step in the wrong direction. Simply put, simple games demonstrate most concepts better than complex games. In fact, it may be desirable to develop games that can be completed in very short periods of time - a concept taught in 5 minutes may be the same as one taught in 20 minutes. Granted, there may be value in working on something over a longer period of time, but in any case, this may be an opportunity for future research.

In conclusion, simulation games provide good learning experiences because students make decisions, see the results of those decisions, and then need to make further decisions based on those results. Results are based on individual decisions as well as on the accumulation of all their decisions. Most simulations involve uncertainty; thus, they are useful tools to acquaint students with this aspect of decision-making.

\section{References}

Applefield, J.M., Huber, R.L. and Moallem, M. (2000). Constructivism in theory and practice: toward a better understanding. High School Journal, vol. 84, no. 2, pp. 35-46.

Bodo, P. (2002). In-class simulations of the iterated prisoner's dilemma game. The Journal of Economic Education, vol. 33, no. 3 , pp. 207-216.

Doyle, D. and Brown, F.W. (2000). Using a business simulation to teach applied skills - The benefits and the challenges of using student teams from multiple countries. Journal of European Industrial Training, vol. 24, no. 6, pp. 330-342.

Faria, A.J. (1998). Business simulation games: Current usage levels - An update. Simulation \& Gaming, vol. 29. no. 3, pp. 295-309.

Gremmen, H. and Potters, J. (1997). Assessing the efficacy of gaming in economic education. The Journal of Economic Education, 28, 4, pp. 291-303.

Heineke, J. and Meile, L. (1995). Games and exercises for operations management: hands-on learning activities for basic concepts and tools. Englewood Cliffs, NJ: Prentice-Hall. 
In-Class Simulation Games

Heineke, J. \& Meile, L. (2000). Classroom service games. Presentation at the Decision Sciences Institute Annual Meeting, Nov. 18.

Kohn, A. (1997). Students don’t ‘work’ - They learn. Education Week, Sept. 3.

Kraiger, K. and Cannon-Bowers, J.A. (1995). Measuring knowledge organization as a method for assessing learning during training. Human Factors, vol. 37. no. 4, pp. 804-812.

Levine, B. (1998). Leadout: An experience in leadership. Simulation \& Gaming, vol. 29, no. 3, pp. 367-369.

McCune, J. (1998). The game of business. Management Review. vol. 87, no. 2, pp. 56-58.

McKeachie, W. (1994). Teaching tips: Strategies, research, and theory for college and university teachers. Lexington, MA: D.C. Heath and Company.

Neal, D.J. (1997). Group competitiveness and cohesion in a business simulation. Simulation \& Gaming, vol. 28, no. 4, pp. 460-476.

Passman, R. (2001). Experiences with student-centered teaching and learning in high-stakes assessment environments. Education, vol. 122, no. 1, pp.189-199.

Reall, M.J., Bailey, J.J. and Stoll, S.K. (1998). Moral reasoning "on hold" during a competitive game. Journal of Business Ethics, vol. 17. no. 11, pp. 1205-1210.

Santos, J. (2002). Developing and implementing an internet-based financial system simulation game. The Journal of Economic Education, vol. 33, no. 1, pp. 31-40.

Schwartzman, R. (1997). Gaming serves as a model for improving learning. Education, vol. 118, no. 1, pp. 9-18.

Silver, E., Pyke, D., and Peterson, R. (1998). Inventory management and production planning and scheduling. New York: John Wiley \& Sons.

Teach, R. (1993). What do we teach when we use games? In Percival, F.; Lodge, S.; and Saunders, D. (eds.) The Simulation and Gaming Yearbook. London: Kogan Page.

Westbrook, J.I. and Braithwaite, J. (2001). The health care game: An evaluation of a heuristic, web-based simulation. Journal of Interactive Learning Research, vol. 12, no. 1, pp. 89-100.

Wolfe, J. and Chanin, M. (1993). The integration of functional and strategic management skills in a business game learning environment. Simulation \& Gaming, vol. 24, no. 1, pp. 34-46.
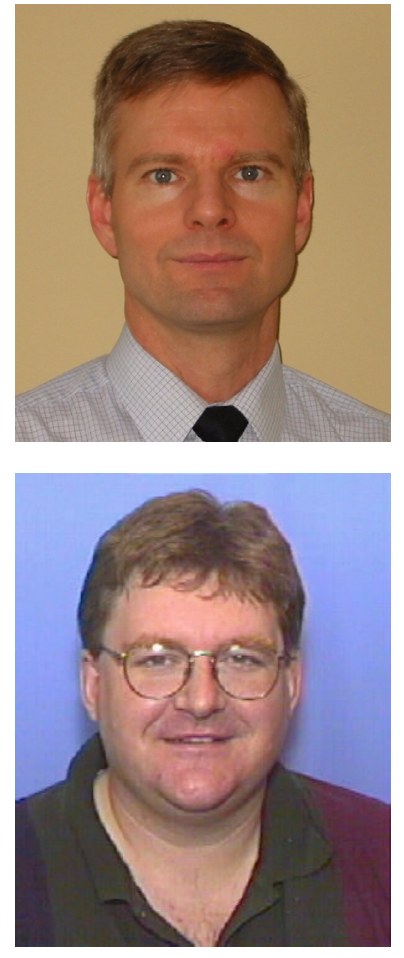

10

\section{Biographies}

Kenneth J. Klassen is an Assistant Professor of Operations management at Brock University. He received a Ph.D. in Operations Management at the University of Calgary. His teaching and research interests focus primarily on operations management in services. He has developed introductory and advanced courses in service operations, and also taught computer simulation and statistics courses. Research involves modeling in a number of areas, including outpatient appointment scheduling, demand and capacity management for services, planning campus parking and food services, and web log analysis.

Keith A. Willoughby is an Assistant Professor in the Department of Management at Bucknell University. He teaches Operations Management, Decision Sciences and a first-year seminar on the "Science of Sports". He received his Ph.D. in Operations Management from the University of Calgary. Previous to this, he was employed as a transportation consultant with the Vancouver Regional Transit System. His research interests include the application of quantitative approaches in project management, public transit system analysis, and sports, as well as the development of teaching materials in Operations Management. 


\section{Appendix 1: Student Instructions for the Game \\ "Il Lance, Il Compte"}

At a recent trade show, a French company unveiled its radical new product for the sports equipment industry - a graphite hockey stick! The company, known as "Il Lance, Il Compte" (rough translation of "He Shoots, He Scores") has enthusiastic plans for the stick. As owners of a medium-sized retail sporting goods store, you (the student participants) are keenly aware of the various costs involved in ordering and holding inventory. Taking into account the respective costs, you are to develop an appropriate ordering policy for this brand-new item.

Since this is a new product, you have no historical data on which to base your forecast of demand. However, you are aware that hockey sticks are seasonal items. Based on sales of other winter sports equipment, you observe that sales follow three 4-month "seasons". These seasons are:

- strong peak: September - December (inclusive)

- weak peak: January - April (inclusive)

- slow: May - August (inclusive)

Your best bet as to demand during these periods is that it will follow a "uniform" distribution, with the following parameters:

- strong peak: $[40,70]$

- weak peak: $[20,45]$

- slow: $[5,25]$

Consequently, the graphite hockey sticks demand during the month of September could fall anywhere between 40 and 70 (any demand can occur with equal probability in that interval). It will never be lower than 40 , nor higher than 70. If it were the month of June, demand could be anywhere between 5 and 25 (never lower than 5, never higher than 25).

"Il Lance, Il Compte" will allow you to purchase hockey sticks for \$20. Market research results given at the recent trade show indicated that potential customers would pay up to $\$ 30$ for the item. Thus, you plan to use $\$ 30$ as your selling price. Note that the amount you sell in a given month is always the lowest of either monthly demand, or beginning inventory + quantity ordered.

Placing an order costs you $\$ 60$ (note that the manufacturer allows at most one replenishment per month). Any unsatisfied demand (a stockout) costs you $\$ 7$ per unit short in addition to the foregone profit on this lost sale. Backorders are not allowed (since customers will most likely purchase the hockey stick from a competitor if you don't have enough on-hand). Inventory remaining at the end of a month costs you $\$ 1$ per unit.

Your task is to plan replenishments (when to order, how much to order) on a month-by-month basis for the next 12 months. Assume that the first month in the planning horizon is July, and that there is no inventory on-hand. After you make your replenishment decision, the instructor will announce the demand for that month. Then, you may make the decision for next month. Use the attached table to indicate your monthly replenishments, and to tabulate the results of your respective strategy. If a stockout occurs, write " 0 " for the ending inventory, and put a " 0 " for the beginning inventory of the subsequent month. 


\section{Appendix 2: Questionnaire before the Game}

This questionnaire is to be filled out before the inventory game. Its purpose is to evaluate how much students learn from the game. It will NOT be used for grading purposes or impact your course grade for this class in any way.

1. The two main questions that inventory management addresses are:

a.

b.

2. Suppose you manage a clothing store and order 10 shirts of a certain size and color. You also have 5 shirts left from the last order. The selling price is $\$ 10$ (this is a discount retailer). Suppose 20 customers come in to purchase one of those shirts.

What is your revenue?

3. Suppose your need to decide whether to place an order every week or every month. Which of the following would you take into account? (Circle all that apply)

$\begin{array}{lcccc}\begin{array}{l}\text { Cost of } \\ \text { items }\end{array} & \begin{array}{c}\text { Ordering } \\ \text { costs }\end{array} & \begin{array}{c}\text { Holding } \\ \text { costs }\end{array} & \begin{array}{c}\text { Cost of } \\ \text { a stockout }\end{array} & \begin{array}{c}\text { Costs of managing } \\ \text { the inventory }\end{array}\end{array}$

4. How difficult do you think it is to make inventory decisions?

$$
\text { Very easy Easy Moderate Difficult Very difficult }
$$

The following information is important and will NOT be used for grading purposes:

Name: (or other identifier)

Did you read the inventory chapter in the text before class? YES NO

Did you go over or glance at the class notes before answering these questions? YES NO 


\section{Appendix 3: Questionnaire after the Game}

This questionnaire is to be filled out after the inventory game. Its purpose is to evaluate how much students learn from the game. It will NOT be used for grading purposes or impact your course grade for this class in any way.

1. The two main questions that inventory management addresses are:

a.

b.

2. Suppose you manage a clothing store and order 8 shirts of a certain size and color. You also have 4 shirts left from the last order. The selling price is $\$ 10$ (this is a discount retailer). Suppose 18 customers come in to purchase one of those shirts.

What is your revenue?

3. Suppose your need to decide whether to place an order every week or every month. Which of the following would you take into account? (Circle all that apply)

$\begin{array}{ccccc}\begin{array}{c}\text { Cost of } \\ \text { items }\end{array} & \begin{array}{c}\text { Ordering } \\ \text { costs }\end{array} & \begin{array}{c}\text { Holding } \\ \text { costs }\end{array} & \begin{array}{c}\text { Cost of } \\ \text { a stockout }\end{array} & \begin{array}{c}\text { Costs of managing } \\ \text { the inventory }\end{array}\end{array}$

4. How difficult do you think it is to make inventory decisions?

Very easy $\quad$ Easy $\quad$ Moderate Difficult Very difficult

5. Was this game a worthwhile learning experience?

Not at all Somewhat Moderately Very much

6. What is the most important thing you learned from the game?

The following information is important and will NOT be used for grading purposes:

Name: (or other identifier) 